Original Article

\title{
ISOLATION AND PURIFICATION OF APIGENIN FROM ALLIUM FISTULOSUM
}

\author{
TEENA MAGLINE IMMACULATE V. ${ }^{1}$, SHLINI P. ${ }^{*}$, MARY CLARE H. ${ }^{1}$
}

1Department of Biochemistry, Mount Carmel College, Autonomous, Palace Road Bengaluru 560052, Karnataka, India Email: shlinip1@gmail.com

Received: 10 Jun 2020, Revised and Accepted: 16 Aug 2020

\section{ABSTRACT}

Objective: The objective of this study is to optimize the extraction of apigenin $\left(4^{\prime}, 5,7\right.$-trihydroxy-flavone) from Allium fistulosum.

Methods: The present study aims at extracting flavonoids from the plant using methanol as a solvent. Phytochemical screening was performed to analyse the phytochemical constituents present in the extract. Apigenin was isolated from the leaves of $A$. fistulosum and further purified and identified by TLC and HPLC.

Results: Phytochemical screening showed the presence of various constituents like terpenoids, tannins, flavonoids, reducing sugars, phenolics, cardiac glycosides and amino acids. TLC results indicated the presence of apigenin in the plant extract with the $\mathrm{R}_{\mathrm{f}}$ value of 0.88 , which coincided with the standard apigenin of $\mathrm{R}_{\mathrm{f}}$ value 0.83 . HPLC results showed a similarity in the peak of 17.1 min of the standard with the minor peak of 17.324 min of the sample. This proved the presence of apigenin in low quantities.

Conclusion: This present study suggests that Allium fistulosum can be a moderate source of apigenin. This compound was isolated for the first time from this plant.

Keywords: Apigenin, Allium fistulosum, Spring onion, Solvent extraction, Methanol, TLC, HPLC

(C) 2020 The Authors. Published by Innovare Academic Sciences Pvt Ltd. This is an open access article under the CC BY license (http://creativecommons.org/licenses/by/4.0/) DOI: http://dx.doi.org/10.22159/ijcpr.2020v12i5.39769. Journal homepage: https://innovareacademics.in/journals/index.php/ijcpr

\section{INTRODUCTION}

Allium fistulosumis also called the Welsh onion. Commonly known as bunching onion, long green onion, Japanese bunching onion, and spring onion, is a species of evergreen plant growing throughout the year. Its odor and taste is very identical to Allium cepa. But $A$. fistulosum, neither does it shows bulb production nor possesses dense leaves, rather has characteristic hollow leaves and scapes. On the other hand, the Leeks and the Japanese Negi are comparatively bigger in size, while Chives are smaller. A very common vegetable in Asia, where there are many different cultivars, it is usually grown more on a garden scale in Europe and America, mainly for its edible leaves which can be produced throughout the winter if the weather is not too severe [1]

The therapeutic qualities attributed to the welsh onion are many, especially in Chinese medicine. It is used to improve the functioning of internal organs and metabolism and to prolong life. It is further reported to improve eyesight, to aid digestion and perspiration, and to enhance recovery from common colds, headaches, wounds and festering sores. A tea made from the roots is a children's sedative [2] Use of the bulb in the diet impedes internal parasites. Externally, the bulb can be made into a poultice to drain pus from sores, boils and abscesses [3]. The juice of the plant is used as a moth repellent. The whole plant is said to repel insects and moles [4].

Among the 6000 distinct flavonoids present, quercetin, kaempferol, myricetin, apigenin and luteolin are the five most omnipresent plant flavonoids. Apigenin (4', 5, 7-trihydroxy-flavone) is one of the prevalent monomeric flavonoids found in an everyday diet. In view of the substance's backbone structure, apigenin is a flavone, one of the subclasses of flavonoids. Apigenin has interested scientists because of its reduced toxicity and different valuable bioactivities. Apigenin is vastly spread in the plant realm, as it has been found in numerous vegetables, herbs, and organic products. Parsley, vine spinach, celery seed, green celery heart, Chinese celery, and dried oregano are dietary sources with high apigenin content. Other plants in which apigenin has been identified include red and white sorghum, rutabagas, oranges, kumquats, onions, wheat sprouts, tea, and cilantro [5]. In nature, apigenin is usually found in a glycosylated form, with the tricyclic core structure linked to a sugar moiety through hydroxyl groups (O-glycosides) or directly to carbon (C-glycosides). The common apigenin glycosides are apiin, apigenin-7-0-glucoside, apigenin-8-C-glucoside (vitexin), apigenin-6-Cglucoside (isovitexin), apigenin-7-0-neohesperidoside (rhoifolin), and apigenin-6-C-glucoside 8-C-arabinoside (schaftoside) [6].

In the colorectal cancer cell lines HCT116 and DLD1, apigenin up regulated BIM expression and down-regulated $\mathrm{Mcl}-1$ expression, thereby synergizing with the $\mathrm{Bcl}-2$ inhibitor ABT-263 to trigger mitochondrial-dependent cell apoptosis [7]. It is reported that apigenin exposure induced G2/M arrest in imatinib-sensitive K562 cells while arresting imatinib-resistant K562/IMA3 cells in S phase, especially at $100 \mu$ Mapigenin [8]. Chemotherapy drugs, such as cisplatin and paclitaxel are widely used in the clinic for cancer control. To enhance their antitumor effects and to minimize their limitation, co-administration with other targeted drugs has been widely tested and has achieved great success in clinical applications. Studies have shown that co-administration with apigenin significantly enhances the anti-cancer efficacy of chemo drugs and helps overcome their limitations in various types of cancers by targeting multiple signaling pathways [9].

The goal of this project was to identify and isolate the bioactive compound apigenin from the leaves of Allium fistulosum.

\section{MATERIALS AND METHODS}

\section{Chemicals}

Methanol, Fehling's A and Fehling's B solution, $\alpha$-naphthol, Benedict's reagent, sodium hydroxide, copper sulphate, Nitric acid, Ninhydrin reagent, Dragendroff s reagent, ferric chloride, chloroform, sulphuric acid, glacial acetic acid, ammonia, isopropanol, ethanolic ferric chloride and benzene was procured from Fischer Scientific. TLC silica gel plate was of $\mathrm{GF}_{254}$, which was procured from Merck.

\section{Plant source}

The leaves of Spring Onion (Allium fistulosum) were collected from Ulsoor market, Bangalore, Karnataka. India.

\section{Extraction}

The plant extract was prepared from the leaves of Allium fistulosum The dust particles were removed by washing under tap water. The leaves of Allium fistulosum was dried at $60^{\circ} \mathrm{C}$ in the hot air oven and 
made it into fine powder using the mixer grinder. The coarse powder of Allium fistulosum [2.5g (w/v)] was extracted with $80 \%$ methanol using magnetic stirrer for $1 \mathrm{hr}$ and extract was obtained by squeezing through muslin cloth and used for further experimental analysis.

\section{Phytochemical test}

The fresh methanol extract was subjected to various phytochemica screening for the detection of various plant constituents, characterized for their possible bioactive compounds [10]

\section{Test for carbohydrates}

\section{Fehling's test}

The sample extract was treated with Fehling's A and Fehling's B solution and heated in a boiling water bath for $5-10 \mathrm{~min}$ at $60{ }^{\circ} \mathrm{C}$. Appearances of reddish-orange precipitate indicate the presence for carbohydrates [10]

\section{Molisch's test}

The filtrate of the extract, which was diluted using water was treated with a few drops of alcoholic $\alpha$-naphthol solution in a test tube. Formation of the violet ring at the junction indicates the presence of carbohydrates [10]

\section{Benedict's test}

The filtrate of the extract was diluted using water and treated with Benedict's reagent and heated in a boiling water bath for 3-5 min. Orange-red precipitate indicates the presence of reducing sugars [10].

\section{Test for proteins}

\section{Biuret test}

Equal volume of $5 \%$ solution of sodium hydroxide and $1 \%$ copper sulphate was added to sample extract. Appearance of pink or purple colour indicated the presence of proteins and free amino acids [10].

\section{Xanthoproteic test}

The extract was treated with a few drops of conc. Nitric acid Formation of yellow color indicates the presence of proteins [10].

\section{Ninhydrin test}

To the extract, $0.25 \% \mathrm{w} / \mathrm{v}$ ninhydrin reagent was added and boiled for few minutes. Formation of blue color indicates the presence of amino acid [10].

\section{Test for alkaloids (Dragendroff's test)}

A small portion of the sample extract was stirred separately with a few drops of dilute hydrochloric acid and filtered. The filtrate was carefully tested with Dragendroff's reagent (solution of potassium bismuth iodide). Formation of red precipitate indicates the presence of alkaloids [10].

\section{Test for tannis}

Small quantity of sample extract was taken separately in water and tested for the presence of tannins with 5\% ferric chloride solution. Appearance of violet color indicates the presence of tannins.

\section{Test for flavonoids}

On the addition of sodium hydroxide solution to the sample extract, blue or violet coloration indicates anthocyanins; yellow coloration indicates flavanones and yellow or orange coloration indicates flavonoids [11].

\section{Test for terpenoids}

To the sample extract, chloroform and concentrated sulphuric acid were added and checked for a reddish-brown coloration for the confirmation of terpenoids [11]

\section{Test for steroids}

\section{Libemann-burchard reaction}

Sample was mixed with chloroform. To this, acetic acid and few drops of concentrated sulphuric acid was added from the side of the test tube. First red, then blue and finally, green color should appear indicating the presence of steroids [10].

\section{Test for glycosides}

\section{Cardiac glycosides (Keller Killani test)}

To the extract, glacial acetic acid, ferric chloride and concentrated sulphuric acid were added. Appearance of reddish brown color at the junction of the two liquid layers indicates the presence of cardiac glycosides [12].

\section{Anthroquinone glycosides (Borntrager's test)}

To the extract, dilute sulphuric acid was added, boiled and filtered To the cold filtrate, equal volume benzene or chloroform was added. The organic layer was separated and ammonia was added. Ammonical layer should turn pink or red for the presence of anthroquinone glycosides [10]

\section{Test for phenols}

\section{Ferric chloride test}

Extract was treated with few drops of ferric chloride solution. Formation of bluish-black color indicates the presence of phenols [10].

Partial purification of rutin and apigenin by thin-layer chromatography

TLC was carried out to segregate apigenin present inthemethanolic concentrate of Allium fistulosum. TLC was performed on a silica gel plate (silica gel GF254, Merck). 2-5 $\mu$ l of different plant extract was deposited to the origins of TLC plates from the $1.5 \mathrm{~cm}$ of the origin with the help of capillary tubes.

\section{Development of chromatogram}

After the application of the sample on the plates, the plates were kept in TLC glass chamber (solvent saturated) then the mobile phase was allowed to move through the adsorbent phase up to $3 / 4^{\text {th }}$ of the plate. Solvent system used was-Benzene/Acetic acid/water (125:72:3). TLC plates were visualized under ultraviolet light ( $\lambda 254$ and $366 \mathrm{~nm}$ ). Retention values of the different bands were then calculated using the equation:

$$
\mathrm{R}_{\mathrm{f}}=\frac{\text { Distance travelled by component }}{\text { Distance travelled by solvent }}
$$

\section{Preparative thin-layer chromatography}

Silica gel plate was used. The benzene/acetic acid/water (125:72:3) mobile phase solvent system was used for the separation of apigenin. The methanol extract from Allium fistulosum was deposited as a concentrated band $1.5 \mathrm{~cm}$ from the edge of its respective TLC plate and allowed to dry. The TLC plates were placed in the chromatographic chamber. Then the respective spots were scraped and further used for characterization using HPLC.

Identification and purification by high-performance liquid chromatography

The partially purified Apigenin from A. fistulosum was subjected to HPLC technique, which was equipped with the binary pump, UV-Vis detector and automatic column temperature control box. Apigenin: 20 $\mu \mathrm{l}$ of the sample was analyzed. The mobile phase was methanol-waterphosphate acid (30:69.3:0.7, v/v/v) with a flow rate of $1 \mathrm{ml}$ min-1. The wavelength used was $360 \mathrm{~nm}$ and the run time was $30 \mathrm{~min}$ [13].

\section{RESULTS AND DISCUSSION}

In this study, apigenin was isolated from the leaves $A$. fistulosum. This plant is easily available in the market and it possesses wide range of phytochemicals and also for its enormous applications in ethnobotanical uses, pharmacological activities and other miscellaneous uses. Especially apigenin have enormous benefits in the medical field.

\section{Phytochemical analysis}

Methanoilc extract of Allium fistulosum was subjected to phytochemical and pharmacological activities. Their phytochemical 
screening was performed which showed the presence of various constituents like terpenoids, tannins, flavonoids, reducing sugars, phenolics, cardiac glycosides and amino acids (table 1). The phytochemicals present in $A$. fistulosum, which revealed that the crude extract of $A$. fistulosum with ethanol indicated the presence of tannins, alkaloids, phenols, saponins, terpenoids and flavonoids whereas aqueous extract showed the presence of tannins, saponins, terpenoids, phenols but not flavonoids [14]. Therefore, the extraction of flavonoids from the plant source using organic solvent is more effective than inorganic solvents.

Table 1: Phytochemical screening of the plant samples

\begin{tabular}{lcc}
\hline Phytochemical test & Allium fistulosum \\
\hline Fehling's test & ++ \\
Molisch's test & - \\
Benedicts's test & - \\
Biuret's test & - \\
Xanthoproteic test & ++ \\
Ninhydrin test & - \\
Dragendroff's test & + \\
Test for Tannins & + \\
Teat for Flavonoids & - \\
Test for Terpenoids & - \\
Libemann-Burchard's test & + \\
Keller Killani's test & - \\
Borntrager's test & + \\
Test for Phenols & + \\
\hline
\end{tabular}

Analysis and Partial purification of the plant extracts by TLC

Thin-layer chromatography for the methanolic extract of $A$. fistulosumwas performed. TLC profiling of this plant extract denoted an imposing result that guided towards the incidence of a number of phytochemicals (fig. 1). Different solvent systems confirmed the presence of diverse potent biomolecules in these plants. TLC investigation delivers important information about the polarity of the chemical constituents in such a way that compound displaying high $\mathrm{R}_{\mathrm{f}}$ value in the less polar solvent system possess lesser polarity and the compound with less $\mathrm{R}_{\mathrm{f}}$ value possess higher polarity. These potent biomolecules were further analysed using HPLC. The choice of the good solvent system for mobile phase is important Combination and polarity of solvents should be used depending on the class of flavonoids targeted [15].

Qualitative analysis of Allium fistulosum extract was performed using TLC. Bright orange spot was observed under UV light, whereas yellow spot was observed under visible light was observed with an $\mathrm{R}_{\mathrm{f}}$ value of 0.88 , which coincided with the standard apigenin of $\mathrm{R}$ value 0.83 , which confirmed the presence of Apigenin. Partial purification was carried out by preparative thin layer chromatography with the respective solvent system using preparative thin-layer chromatography. This method of isolation required less amount of solvent and we obtained apigenin in adequate quantity.

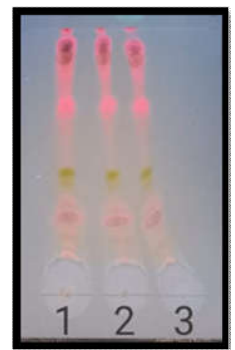

Fig. 1: TLC profiling of Apigenin under long UV (365 nm), Lane 1 , lane 2 and lane 3-crude extracts of $A$. fistulosum

\section{Purification and identification by HPLC}

High-Performance Liquid chromatography was performed to identify the presence of the desired flavonoid compound apigenin. This can be done by comparing the retention time of the peaks with that of the standard compounds (fig. 2). Partially purified sample was subjected to HPLC for further purification and identification of Apigenin in Allium fistulosum extract (table 2). The HPLC system consisted of a binary HPLC pump and the separation was based on $\mathrm{C}-18$ Dynamic column and the column was maintained at $25^{\circ} \mathrm{C}$.

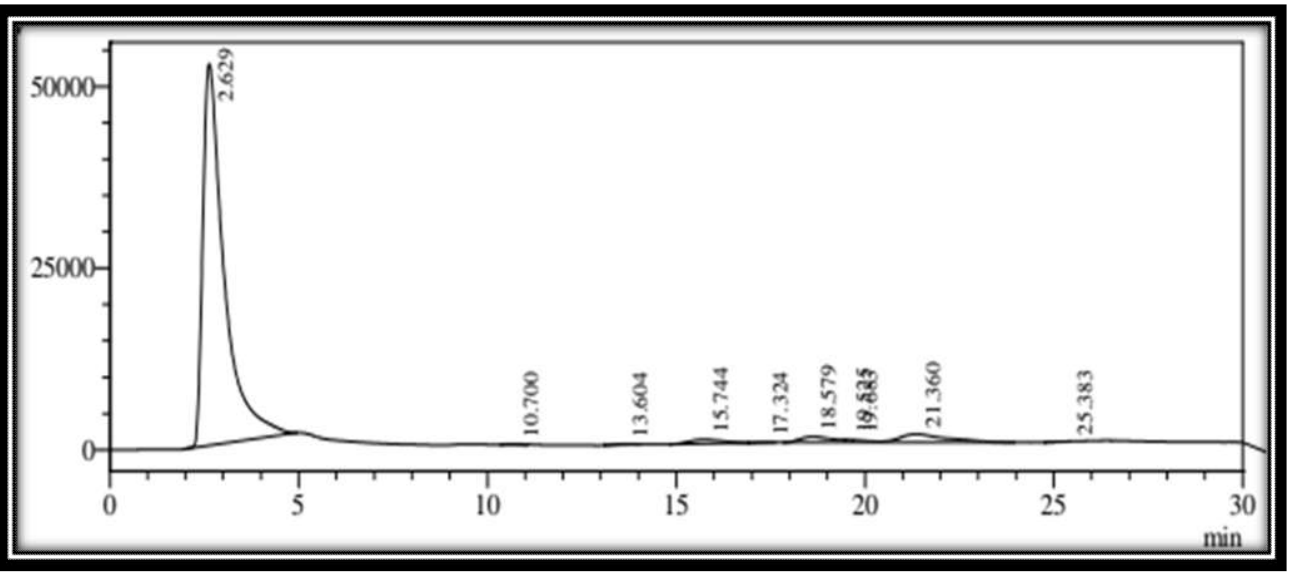

Fig. 2: HPLC Chromatogram of partially purified A. fistulosum 
Table 2: HPLC profile of apigenin isolated from $A$. fistulosum

\begin{tabular}{|c|c|c|c|c|c|}
\hline \multicolumn{6}{|c|}{ Detector A Ch 1360 nm } \\
\hline Peak\# & Ret. Time & Area & Height & Area \% & Height \% \\
\hline 1 & 2.629 & 2065728 & 52510 & 90.845 & 93.612 \\
\hline 2 & 10.700 & 4542 & 143 & 0.200 & 0.255 \\
\hline 3 & 13.604 & 3511 & 110 & 0.154 & 0.196 \\
\hline 4 & 15.744 & 36522 & 587 & 1.606 & 1.047 \\
\hline 5 & 17.324 & 1369 & 55 & 0.060 & 0.097 \\
\hline 6 & 18.579 & 46965 & 799 & 2.065 & 1.425 \\
\hline 7 & 19.525 & 4219 & 377 & 0.186 & 0.672 \\
\hline 8 & 19.683 & 9342 & 354 & 0.411 & 0.632 \\
\hline 9 & 21.360 & 100532 & 1126 & 4.421 & 2.007 \\
\hline 10 & 25.383 & 1172 & 32 & 0.052 & 0.058 \\
\hline Total & & 2273902 & 56094 & 100.000 & 100.000 \\
\hline
\end{tabular}

The demonstrated HPLC chromatogram of the partially purified methanolic extracts of $A$. fistulosum determined the presence of apigenin It showed a similarity in the peak of $17.1 \mathrm{~min}$ of standard with the minor peak of $17.324 \mathrm{~min}$ of the sample [13]. The samples also showed one major peak at 2.629 and 9 minor peaks at $10.700 \mathrm{~min}, 13.604 \mathrm{~min}$ $15.744 \mathrm{~min}, 17.324 \mathrm{~min}, 18.579 \mathrm{~min}, 19.525 \mathrm{~min}, 19.683 \mathrm{~min}, 21.360$ min and $25.383 \mathrm{~min}$. This proved the presence of apigenin in low quantities along with other flavanoids in the extract [13].

\section{CONCLUSION}

The current study was focused at the isolation of apigenin from the leaves of Allium fistuloum. This study showed that their leaves contained different phytochemical constituents. Phytochemical screening of the methanolic extract showed the presence of various constituents like terpenoids, tannins, flavonoids, reducing sugars, phenolics, cardiac glycosides and amino acids, Apigenin was analysed and partially purified from the extract using TLC and preparative TLC method. This investigation using TLC showed the presence of apigenin and it was purified using HPLC technique. Apigenin is considered as an antioxidant compound and it is also commercially available but it is expensive. Allium fistulosum belong to the family Amaryllidaceae, identified as a moderate source of apinenin. Allium fistulosum is cheap and easily available in the market and the method of isolation required less amount of solvent. From this plant, we can obtain apigenin in low quantities but it is not very expensive.

\section{ACKNOWLEDGEMENT}

The authors wish to acknowledge the Department of Chemistry (PG Biochemistry) and the management of Mount Carmel College, Autonomous, Bengaluru offering their facilities for the analysis.

\section{FUNDING}

Nil

\section{AUTHORS CONTRIBUTIONS}

All the authors have contributed equally.

\section{CONFLICT OF INTERESTS}

\section{None}

\section{REFERENCES}

1. Larckom J. Oriental vegetables. John Murray Publishers Limited. London; 1991.
2. Duke JA, Ayensu ES. Medicinal plants of china reference publications. Inc; 1985.

3. Chevallier A. The encyclopedia of herbal medicine dorling kindersley. London; 1996.

4. Riotte L. Companion planting for successful gardening. Garden way. Vermont; 1978.

5. Bhagwat S, Haytowitz DB, Holden JM. USDA database for the flavonoid content of selected foods. U. S. department of agriculture; 2011. p. 1-156.

6. Tang D, Chen K, Huang L, Li J. Pharmacokinetic properties and drug interactions of apigenin, a natural flavone. Expert Opin Drug Metab Toxicol 2017;13 Suppl 3:323-30.

7. Shao H, Jing K, Mahmoud E, Huang H, Fang X, Yu C. Apigenin sensitizes colon cancer cells to the antitumor activity of ABT263. Mol Cancer Ther 2013;12:2640-50.

8. Solmaze S, Gokbulut AA, Cincin B, Ozdogu H, Boga C, Cakmakoglu B, et al. Therapeutic potential of apigenin, a plant flavonoid, for imatinib-sensitive and resistant chronic myeloid leukemiacells. Nutr Cancer 2014;66:599-612.

9. Gaballah HH, Gaber RA, Mohamed DA. Apigenin potentiates the antitumor activity of 5-FU on solid Ehrlich carcinoma: crosstalk between apoptotic and JNK-mediated autophagic cell death platforms. Toxicol Appl Pharmacol 2017;316:27-35.

10. Khandelwal KR. Practical pharmacognosy, techniques and experiments. $13^{\text {th }}$ Edition. Nirali Prakashan, Pune, India; 2005.

11. Edeoga HO, Okwu DE, Mbaebie BO. Phytochemical constituents of some nigerian medicinal plants. Afr J Biotechnol 2005;4:685-8.

12. Aiyelaagbe 00, Osamudimen PM. Phytochemical screening for active compounds in Magniferaindica leaves from Ibadan oyo state. Medwell J 2009;2:11-3.

13. Wang $\mathrm{H}$, Yang L, Yuangang $\mathrm{Zu}$, Zhao X. Microwave-assisted simultaneous extraction of luteolin and apigenin from tree peony pod and evaluation of its antioxidant activity. Sci World J 2014;12. https://doi.org/10.1155/2014/506971.

14. Alagarsamy S, Chellappan P, Jesuraj MT, Mohan MSG, Balakrishnan R. Phytochemical screening and the antioxidant potential of the crude extract of allium oschaniniiscape. Oreintal Pharm Exp Med 2018;18:309-16.

15. Awouafack MD, Tane $\mathrm{P}$, Morita $\mathrm{H}$. Isolation and structural characterization of flavonoids, flavonoids-from biosynthesis to human health. Goncalo C Justino Intech Open; 2017. Doi:10.5772/67881. 